\title{
VOGAIS TEMÁTICAS, GÊNERO E CONCORDÂNCIA NOMINAL EM PLE
}

\author{
Thematic Vowels, Gender and Nominal Agreement in Portuguese Foreign \\ Language
}

\section{Diocleciano NHATUVE ${ }^{1}$}

RESUMO: Este artigo discute a relação entre vogais temáticas, gênero e concordância em Português como língua estrangeira. O objetivo é identificar as tendências no estabelecimento da concordância e as características dos nomes com os quais ocorre maior número de desvios de concordância nominal em gênero em sintagmas nominais dos aprendizes zimbabweanos de português, cujo conhecimento linguístico prévio envolve aspetos de shona e de inglês, com mecanismos de concordância distantes dos do português e, assim, verificar até que ponto coincidem ou se distanciam dos resultados de outros estudos semelhantes. O estudo baseia-se numa abordagem mista, de tal sorte que os resultados são de natureza qualitativa e quantitativa. Como resultado o estudo revela que as vogais temáticas não influem no estabelecimento da concordância em PLE dos aprendentes zimbabweanos. Neste grupo, grande parte dos nomes terminados por $-a$ é associada a acessórios com traços do masculino, revelando-se a tendência de usar o masculino independentemente da vogal. Desta feita, à tendência revelada por Leiria (2006), Ferreira (2011) e Pinto (2012), a qual indica que o desvio de concordância em gênero se concentra em nomes que não terminam pelas vogais $-a \mathrm{e}-o$, acrescenta-se mais um dado diferente sobre as vogais temáticas e a concordância em gênero.

PALAVRAS-CHAVE: Vogais temáticas; Gênero; Concordância nominal em PLE.

ABSTRACT: This article discusses the thematic vowels, gender and nominal agreement in Portuguese as a foreign language. The objective is to identify nominal agreement tendencies and characteristics of the nouns with which many gender nominal agreement deviations occur within noun phrases written by Zimbabwean learners of portuguese, whose previous linguistic knowledge involves aspects of Shona and English, with different agreement mechanisms from the Portuguese ones. This allows us to verify to which extent they diverge or converge from other studies with similar outcomes. The study is based on a mixed approach with qualitative and quantitative results. As a result of this study, it is revealed that within the targeted group, thematic vowels do not sway trends of gender nominal agreement in Portuguese as a foreign language. In this group, a huge number of nouns ending by- $a$ is associated to determiners and modifiers in masculine., illustrating the tendency of using masculine independently of the gender of the noun. In this case, to the assumption revealed by Leiria (2006); Ferreira (2011) and Pinto (2012), which indicates that gender nominal agreement deviations are concentrated in names that do not end by thematic vowels $-a$ and $-O$, one more different aspect regarding vowels and gender agreement is added.

\footnotetext{
${ }^{1}$ Leitor de Língua Portuguesa na Universidade do Zimbabwe ; Doutorando em Língua Portuguesa: Investigação e Ensino - Universidade de Coimbra. djrnhatuve@gmail.com
} 
KEYWORDS: Thematic vowels; Gender; Gender nominal agreement in Portuguese as a foreign language.

\section{INTRODUÇÃO}

A heterogeneidade sociolinguística dos diferentes grupos que aprendem o português língua não materna (PLNM) no mundo implica, em paralelo, a heterogeneidade dos aspetos linguísticos e pedagógicos que surgem no âmbito do ensino-aprendizagem do português. Aliás, os problemas da sintaxe e da fonologia que se colocam a aprendentes de português língua segunda (PLS), por exemplo, não são necessariamente os mesmos dos aprendentes de portuguesa língua estrangeira (PLE). No que diz respeito à relação tripartida vogais temáticas (VT), gênero e concordância, há estudos de PLE que revelam como nomes propensos a desvios de concordância em gênero aqueles que não terminam pelas VT $-a \mathrm{e}-o$ associadas geralmente ao feminino e ao masculino, respectivamente (LEIRIA, 2006; PINTO, 2012; FERREIRA, 2011).

O objetivo deste trabalho é, portanto, analisar a concordância nominal em gênero (CNG) em PLE de um grupo sociolinguisticamente diferente dos que foram estudados por aqueles autores, para verificar até que ponto as VT constituem um aspeto relevante no estabelecimento da CNG. Neste âmbito, para a realização deste objetivo geral, procurar-se-á identificar a relação entre os índices temáticos dos nomes e os aspetos de concordância em gênero no interior de sintagma nominal (SN). Procurar-se-á, igualmente, verificar o nível de desvios nas palavras com terminações $-a$ e $-o$ bem como as características das unidades lexicais em que se registra grande número de desvios de $\mathrm{CNG}$.

A pertinência deste trabalho reside no fato de, em primeiro lugar, contribuir para a construção e divulgação do conhecimento sobre o ensino de PLE e sobre os aspetos que caracterizam um grupo específico de aprendentes; em segundo, no fato de apresentar dados particulares de aprendentes de PLE, falantes de uma língua bantu e de inglês, os quais revelam aspetos diferentes dos outros grupos e, desta forma, contribuir para a discussão sobre a relação VT e concordância em gênero. Assim, permitir-se-á a concepção de estratégias de ensino-aprendizagem baseadas em fatos específicos por 
parte de profissionais de ensino, colmatando, desse modo, a generalização dos aspetos que caracterizam o PLE, por falta de estudos particulares para cada grupo.

Para tal, analisam-se SNs produzidos por estudantes do PLE na Universidade do Zimbabwe. Em termos sociolinguísticos, este grupo alvo é caracterizado por ser falante de duas línguas com características diferentes entre si e entre elas e o português no que tange à flexão dos nomes em gênero e ao fenômeno de concordância nominal. Trata-se de shona como língua materna e de inglês como língua segunda. Entretanto, o conhecimento linguístico prévio (CLP) na base doensino-aprendizagem de português é de caráter heterogêneo e distante do português.

Enquanto em shona, maior número de palavras termina por vogal, em inglês não se pode dizer o mesmo. Aliás, o CLP do grupoalvo caracteriza-se pela convergência de aspetos sintáticos do shona - em que se verificam a ausência de artigos (MHUTE, 2011), um sistema de gênero baseado em classes nominais (DÉCHAINE, 2013) e fenômenos de flexão e concordância nominais baseados no processo de prefixação, excetuando casos dos demonstrativos cujos morfemas que desencadeiam a concordância com o nome se colocam em frente de uma vogal (MKANGWANWI, 2002) - e do inglês - língua em que, de uma forma geral, os especificadores e modificadores nominais não se flexionam nem concordam em gênero com o núcleo nominal (WAGNER, 2003).

Naturalmente, considerando que quer um quer outro sistema (que constituem o CLP dos alunos) se distancia do sistema português, são previsíveis dificuldades no estabelecimento da CNG em PLE, atribuíveis a efeitos de transferência linguística que se traduzem 1. Em mecanismos que se têm vindo a revelar transversais aos aprendentes de PLNM, nomeadamente a atribuição, por defeito, do valor de gênero masculino ao nome e aos seus acessórios; 2. o estabelecimento da CNG em função da VT do núcleo, o que, não raras vezes, conduz a desvios de concordância; 3. ou a preferência pela marcação de valor de número plural nos especificadores (em detrimento da sua marcação no próprio nome) entre outros.

\section{PROBLEMATIZAÇÃO}

A partir das últimas décadas do século $\mathrm{XX}$, o ensino-aprendizagem do PLE expandiu-se consideravelmente na Europa, nas Américas, na Ásia e na África, 
territórios com diversidades sociolinguísticas e culturais particulares a considerar. No entanto, desde então, o ritmo de expansão de ensino de PLE no mundo, não ocorre em paralelo com estudos científicos quer dos aspetos sociolinguísticos dos novos aprendentes quer de aspetos de PLE que sobressaem no âmbito de ensino-aprendizagem e contato linguístico que se espera. Esta situação conduz amiúde a generalização, por parte dos sistemas - professores e organismos que tutelam o ensino de PLE - dos aspetos, dos materiais e, até certo ponto, das estratégias a considerar no ensino de PLE.

No que tange à relação entre concordância nominal e VT, estudos disponíveis efetuados por LEIRIA (2006), FERREIRA (2011) e PINTO (2012), entre outros, cujos grupos alvo eram compostos por aprendentes de PLE chineses, alemães, marroquinos, espanhóis, ucranianos, respectivamente, falantes de cantonês ou mandarim, de alemão, de árabe ou amazigh, de espanhol e de ucraniano como língua materna, revelaram que os desvios de CNG se concentravam em nomes que não terminassem pelas VT $-a \mathrm{e}-o$ tradicionalmente associadas respectivamente ao feminino e ao masculino; isto é, em nomes terminados com aquelas vogais, o desvio é significativamente reduzido.Esta disposição leva a considerar a hipótese de que em PLE, os problemas de CNG têm a vercom as terminações das palavras. Assim, desencadeia-se uma discussão, considerando-se a já conhecida hipótese segundo a qual os problemas de CNG têm a ver com a tendência de generalização do uso do masculino.

No entanto, no que diz respeito ao PLE, a discussão despoletada, é bloqueada pela ausência de estudos que demonstrem outras tendências diferentes das que foram apresentadas por aqueles autores.Não tendo encontrado trabalhos que indicassem uma outra tendência respeitante à relação VT e CNG e considerando o CLP dos aprendenteszimbabweanos de PLE, falantes de shona e de inglês em cujos sistemas de concordância nominal, muito distantes do português, as VT não são pertinentes na CNG, com o intuito de contribuir para a discussão exposta, levantam-se questões como:

1. Há alguma relação entre as VT e a CNG em PLE dos falantes de shona e de inglês?

2. Como se manifesta a CNG dos aprendentes zimbabweanos de PLE neste âmbito? 
3. A tendência de concentração do desvio em nomes que não respeitam as terminações $-a e-o$ é geral para os aprendentes de PLE, ou se trata de um aspeto particular a certos grupos?

4. Os desvios registrados explicam-se pela relação $V T$ e $C N G$, ou pela tendência de usar o masculino independentemente do gênero do núcleo?

A resposta às questões ora colocadas envolve aspetos sociolinguísticos, pedagógicos e, até certo ponto, culturais considerando que cada grupo de aprendentes tem um perfil sociolinguístico particular e que o CLP desempenha, de maneiras diferentes, papéis na aprendizagem do português. Desta feita, colocam-se para validação várias hipóteses no âmbito da relação CNG e VT, dentre as quais se indicam:

1. para os aprendentes zimbabweanos de português, em cuja língua materna (shona) as vogais com que terminam os nomes não têm a ver nem com o gênero nem com o fenômeno de concordância e; em cuja segunda língua (inglês) não se prevê a $\mathrm{CNG}$ no $\mathrm{SN}$, a marcação do gênero e o estabelecimento da CNG não têm ligação com a natureza das VT ou terminações dos nomes;

2. a explicação dos desvios na CNG em PLE dos aprendentes zimbabweanos não corresponde necessariamente à explicação baseada na não correspondência das terminações dos nomes às VT $-a$ e $-O$ apresentada por alguns autores;

3. mais do que na dependência da CNG das VT, o desvio de CNG no seio dos aprendentes zimbabweanos consiste na tendência de generalizar o uso do masculino;

4. a concentração dos desvios de gênero em nomes com terminações não regulares (consoante, ditongo, etc.) é uma tendência geral dos aprendentes de PLE.

\section{ENQUADRAMENTO TEÓRICO}

Duas teorias (em combinação) estão na base deste estudo. Trata-se da teoria de variação linguística de origem laboviana e da teoria de ensino aprendizagem das línguas estrangeiras. A combinação das duas fundamenta-se pelo fato de ambas oferecerem explicação para as realizações linguísticas desviantes que se registram na aprendizagem 
e uso de LE e, no caso particular, do PLE. As duas convergem ao prever a ocorrência de fenômenos de variação na aquisição de novos idiomas e ao considerar que os fatores sociolinguísticos desempenham um papel na performance linguística dos aprendentes de LE, sobretudo nos primeiros anos.

Na sociolinguística laboviana, cujo objeto é “(...) a língua, o instrumento que as pessoas usam para se comunicar com os outros na vida quotidiana, (...) alvo do trabalho em Variação Linguística.” (LABOV, 2007, p. 3), podem se destacar duas grandes perspetivas de análise sociolinguística, nomeadamente, a sociolinguística histórica, a qual se preocupa como a mudança da língua ao longo do tempo e cujas fontes são marcadamente artefactos escritos, e a sociolinguística variacionista, cujo objeto é "a descrição das diferentes variedades que coexistem dentro de uma comunidade de fala, relacionando-as com as estruturas sociais; (...) 'engloba praticamente tudo o que diz respeito ao estudo da linguagem em seu contexto social"” (BAYLON, 1991 apud. SALOMÃO, 2011, p. 189).

Por sua vez, a teoria de aprendizagem das línguas estrangeiras, preconiza a ocorrência do processo (ensino-aprendizagem) depois do desenvolvimento, pelo menos, da língua materna dos indivíduos (cf. LEIRIA, 2005 e KLEIN, 1989, p. 33) e, por conta disso, tal como afirmamS. Sridhar e KamalSridhar (1986, 1994 apud GONÇALVES 2010, p. 18), o meio envolvente desempenha um papel preponderante, realçando o valor "dos objetivos e a motivação dos aprendentes, e ainda a qualidade do input a que estão expostos". É, na verdade, os inputs, quer de português na escola quer de shona e inglês na sociedade e na família e a sua relação, que condicionam o fenômeno de variação (mudança) na língua em aprendizagem, neste caso, o português.

\section{REVISÃO BIBLIOGRÁFICA}

A marcação do gênero não consiste em processos universais. Há, no entanto, dois critérios que importam reiterar: 1. "languages may use semantic rules or, [2.] semantic and formal rules; but not only formal assignment rules ${ }^{2}$ (CORBETT, 2006, p. 752). A língua portuguesa segue, pelos vistos, o segundo critério, uma vez que o gênero precisa de ser expresso morfológica e/ou sintaticamente. Por falar na expressão morfológica ou sintática do gênero, interessa referir que, sob o ponto de vista das

\footnotetext{
2 Tradução livre: "As línguas podem usar critérios semânticos ou, critérios semânticos e formais; no entanto, nunca critérios formais isolados."
} 
terminações, podendo os nomes apresentarem os índices temáticos: (1.) - a (Almeida, profeta, sala, aluna, faca, etc.), (2.) -e (pente, gente, semente, gabinete, fonte, etc.), (3) $o$ (conto, método, século, copo, etc.) e (4) tema zero (cantor, lençol, mar, professor, etc.), há uma tendência generalizada de associar as vogais temáticas - $a$ com o feminino $\mathrm{e}-O$ com o masculino.

No entanto, existem evidências suficientes para demonstrar a não funcionalidade deste critério para a identificação, marcação e distinção do gênero dos nomes. Observando os exemplos acima, verifica-se que muitos nomes terminados em $-a$ não são do gênero feminino e muitos outros terminados por outros índices temáticos são do gênero feminino ( $c f$.VILALVA, 20037 , p.922-924 e RIO-TORTO,2001).

$\mathrm{O}$ fato de as vogais temáticas não rotularem necessariamente a categoria gramatical de gênero e o fato de não existirem critérios consistentes e transparentes da marcação do feminino e do masculino enfatizam a arbitrariedade e a irregularidade da marcação do gênero em português. Com efeito, o fenômeno de concordância sintática em gênero, que depende, em parte, dos processos de marcação do gênero, torna-se pouco claro e incompreensível devido a não sistematicidade dos critérios de marcação do gênero ( $c f *$ a problema, *a mapa).

Ademais, "although agreement is systematically related to the gender of a noun, this gender itself is often arbitrary, i.e., not systematically related to other properties of the noun or its referent ${ }^{3 "}$ (VAN BERKUM, 1996).

Efetivamente, alguns autores reprovam, devido às suas fragilidades, os processos morfológicos de marcação do gênero em português baseados no uso dos morfemas - $a$ e - oque também funcionam como índices temáticos. A professora Graça Rio-Torto (2001 p.263) argumenta que "na tradição gramatical estes morfemas $\left[\begin{array}{lll}-a & \mathrm{e} & -o\end{array}\right]$ são indevidamente considerados sufixos de gênero. Não se trata efetivamente de operadores de género, pois este é, de fato, determinado pelo determinante que se encontra à esquerda do nome". Por seu turno Lucchesi (2009, p. 2996).considera que a indicação mórfica da categoria de gênero "é feita exclusivamente através da concordância, na medida em que a maioria dos nomes não porta nenhuma marca formal de gênero (...). Portanto, a análise da categoria gramatical do gênero compreende, por um lado, a sua

\footnotetext{
3 Tradução livre:’Embora a concordância seja semanticamente relacionada com o gênero do nome, muitas das vezes, tal gênero é arbitrários; isto é, não está semanticamente relacionado com outras propriedades do nome ou do respetivo referente."
} 
estruturação no léxico da língua e, por outro lado, a sua manifestação na estrutura sintagmática da sentença."

A tentativa de ligação do gênero gramatical com a realidade encontra sempre obstáculos difíceis de transpor. Segundo Vilalva (20037 , p. 929), quando o gênero estiver associado aos nomes de seres animados, estabelece-se a correspondência do gênero com o sexo e excetuam-se logo as plantas. Ademais, o gênero gramatical realizase também com nomes de seres inanimados e abstratos, logo sem a possibilidade de estabelecer uma relação com o sexo. Claramente, na relação gênero e seres animados, os morfemas $-o$ e $-a$ em nomes como pato/pata "denotam diferenças de sexo biológico dos respetivos referentes extralinguísticos sendo, assim, semanticamente motivados; mas tal também sucede em o/a modelo, o/a jornalista, o/a estudante ou em cavalo/égua sem que, nestes casos, se recorra, no domínio da forma nominal, a mecanismos flexionais (ou sequer morfológicos) para o efeito" (MARTINS, 2015).

Fica claro que o recurso a VT não é suficiente para desencadear a marcação do gêneroquer ao nível lexical quer ao nível sintagmático e muito menos para oferecer uma explicação exaustiva e isenta de críticas de ordem morfossintática. Se nomes terminados pela VT- $a$ (atleta) podem ser do gênero gramatical masculino e os terminados pela VT$o$ (tribo) podem ser do feminino, então desenha-se com maior significância a necessidade de separação entre as VT e os morfemas de gênero que, equivocamente, têm sido, amiúde, confundidos.

Se o morfema -asó muda para o feminino algunsnomes, regra geral, devido a circunstâncias de sexualidade dos seus referentes ( $c f$. FERREIRA, op. cit.); se não há possibilidade de marcar o masculino recorrendo ao uso do morfema - $o$ em palavras femininas; se se considerar que os nomes epicenos e sobrecomuns, "cujos referentes são também sexuados, não conhecem variação de gênero gramatical que reflita as diferenças de sexo dos respetivos referentes (águia $\mathrm{fem}_{\mathrm{f}}$ águia-machofem;criança $a_{\mathrm{fem}}$ (do sexo feminino)/criança $a_{\mathrm{fem}}$ (do sexo masculino))" (MARTINS, 2015) em que nenhum daqueles morfemas modifica o gênero das palavras e, se não se trata de uma categoria de flexão motivada na maior parte dos casos, então parece se tratar de uma categoria que se projeta seguramente por mecanismos sintáticos (CS) (cf. FERREIRA, 2011) e não flexionais ( $c f$. VILALVA, 1994). Isto é, a variação em gênero mostra-se mais nitidamente em contexto sintático do que através de flexão morfológica ( $c f$. LUCCHESI, 2009, p. 296-8). 
Portanto, apesar de todos os nomes em português terem gênero, nem todos admitem o contraste de gênero ( $c f$. Ferreira 2011: 28). A questão de gênero e a sua marcação em português não pode ser vista e considerada superficialmente na perspetiva da morfologia flexional tendo em conta todas as fragilidades supra mencionadas. Antes e, praticamente sem pontos de incertezas, os fenômenos que permitem a identificação inequívoca do gênero em português são os morfossintáticos (VILALVA, 1994;LUCCHESI, 2009; FERREIRA, 2011). É, neste contexto, que Leiria (2006), Pinto (2012) e Ferreira (2011) analisam os dados de PLE e demonstram que é nos nomes que não terminam com aquelas vogais confundidas com índices de gênero que se verifica maior número de desvios de CNG.

\section{METODOLOGIA}

Este estudo consiste na análise de SNs extraídos em textos escritos por aprendentes de PLE do $2^{\circ}$ e $3^{\circ}$ anos na Universidade do Zimbabwe, considerando os aspetos de CNG e a sua relação com as VTs -a e -o. Os textos são de autoria de 39 estudantes, sendo 21 do segundo ano e 18 do $3^{\circ}$, com idades compreendidas entre os 18 e os 30 anos. Do total dos informantes, 27 correspondentes a $69 \%$ são do sexo feminino enquanto os restantes 12 equivalentes a $31 \%$ são homens. Este grupo de estudantes aprende português como uma das cadeiras dos diferentes cursos de bacharelato que estão a seguir na Universidade, regra geral, o único espaço em que tem acesso ao português no contexto da sala de aula. A média de tempo de aprendizagem é de 3 e 5 semestres letivos, respectivamente para os estudantes do segundo e do terceiro ano.

Os textos, escritos em contextos de ensino-aprendizagem (redações em sala de aula, em casa e em testes) são de diversos temas. Aos alunos foi dada a instrução de escrever uma redação (de uma média de 150 palavras) sobre um dos seguintes temas: férias do natal, descrição de um amigo; experiência na Universidade, amizade, entre outros. A opção por textos escritos em diferentes contextos (casa e escola) justifica-se pela necessidade de verificar se o contexto tinha alguma influência ou não na realização desviante do fenômeno de CNG - neste aspeto, quer textos escritos em casa quer os que foram escritos na sala apresentam o mesmo tipo de desvio. Os alunos não formam informados que os seus manuscritos seriam objeto de estudos linguísticos aquando da elaboração das redações; esta informação só lhes foi dada no memento de solicitação da 
sua autorização para o uso dos seus textos para fins investigativos. Por sua vez, a opção pela variação dos temas tem a ver com a necessidade de abranger maior número de contextos linguísticos em que é necessário estabelecer a CNG. Assim se evita trabalhar com o mesmo tipo de desvio de CNG, como por exemplo, a concordância entre o predicativo e o sujeito, frequente em textos descritivos.

Os SNs são agrupados em função das seguintes terminações: $-a$; - $o$; e outras terminações (ditongo e consoante), para verificar em que contexto se concentra o desvio CNG bem como a sua descrição linguística. A apresentação dos dados é reforçada pela indicação de exemplos para facilitar a compreensão dos aspetos salientes e pela representação gráfica que permite a identificação dos desníveis das tendências no estabelecimento da CNG.

Portanto, o estudo consiste numa abordagem mista em que se associam a análise qualitativa e quantitativa dos dados. Aliás, como postulado por Silveira e Córdova, apoiando-se em Fonseca (2007)

a utilização conjunta da pesquisa qualitativa e quantitativa permite recolher mais informações do que se poderia conseguir isoladamente (...) como visto até aqui, tanto a pesquisa quantitativa quanto a pesquisa qualitativa apresentam diferenças com pontos fracos e fortes. Contudo, os elementos fortes de um complementam as fraquezas do outro, fundamentais ao maior desenvolvimento da Ciência (FONSECA, 2002 apud. SILVEIRA e CÓRDOVA, 2009, p. 33-34).

\section{APRESENTAÇÃO DE DADOS}

Os dados sobre a relação entre CNG e as VT indicam a ocorrência de uma esmagadora maioria de SNs com nomes terminados por - $a$ associados a acessórios (especificadores e modificadores) com traços gramaticais de masculino, como nos exemplos abaixo:

\section{Exemplos 1}

a. *Eu [sv vou organizar [sN um grande festa]. PII16SI47 (F768)

b. * [SN um pessoa simpático]. PII16SI35 (F502)

c. *[sv Bebíamos [sNmuito bebidas]]. PII14/15/16SI/II52 (F859)

d. *[sv Tinha também [sNmuito amigas]]. PII14/15/16SI/II52 (F857) 


\section{e. *Eu [sv fazia [sN muito coisas]]. PII14/15/16SI/II52 (F864)}

f. *e toma pequeno almoço [sP com os seus famílias]. PII15SII16 (F261)

g. *A cidade [sv tem [sNmuito escolas privado e colégios]]. PIII17SII42 (F8789)

h. *[sN-Suj. A cidade sem amor cheio] de crianças das ruas, órfões e viúvas sem abrigo, comida é roupas. PIII17SII31 (F670)

i. *preparar [sNum grande festa]] por o jantar. PIII17SII29 (F625)

j. *[FA verdadeira amizade dever ser simpático], divertido, maduro, e não ciumento, aborecido e o tédio *PIII17SII25 (F579)

k. *Infelizmente, [Foutras disputas são muito sério] PIII17SII24 (F540)

De um universo de 368 ocorrências (considerando textos dos dois grupos) desviantes no que concerne à categoria de gênero, 228 correspondentes a $61.9 \%$ concernem às estruturas cujos núcleos nominais terminam pela vogal temática $-a$ (vd. Gráfico 1), sendo apenas 19 (5.1\%) em que a não coincidência entre a VT - $a$ e o gênero feminino do nome pode ser vista como a causa do desvio. Trata-se de nomes como poema (*a poema) ou cinema (* a cinema) que terminando em -anão pertencem ao feminino. Os restantes núcleos nominais terminados com aquela VT e sendo do feminino são expandidos por elementos não marcados em gênero. Este comportamento ilustra, uma clara tendência do uso do masculino no estabelecimento da CNG.

Por sua vez, foram registradas 35 (correspondentes a 9.5\%) ocorrências de desvios envolvendo SNs com núcleos com o índice temático $-o$. Neste caso, estes nomes pertencentes ao gênero morfológico masculino são associadas a especificadores e modificadores do feminino, como ilustram os exemplos 2. Entretanto, neste grupo não se verificou nenhum caso de desvio resultado da tendência de fazer corresponder o gênero dos elementos acessórios do nome com um gênero falsamente projetado pela VT como em Tribo (*o tribo). Ora, o reduzido número de casos em que nomes do masculino são combinados com elementos no feminino reforça a ideia de preferência pelo gênero masculino.

\section{Exemplos 2}

1. *quer do garmente branco [SN as fatos brilhantes], PII15SII3 (F71)

2. *Também, ele [sv tem o nariz grande e [snuma sorriso lindo]]. PII16SI36 (F522)

3. *Eu gostaria [sv tocar [sNa piano] PII14/15/16SI/II52 (F904)

4. *Nós [sv estamos usar [sN uma carro]]. PII16SI2 (F53) 
5. *e [sv limpa [sN a sua quarto]] de dormir e a casa. PII15SII12 (F193)

6. *[sv Temos [snduas carros] na minha família. H PII14/15/16SI/II52 (F1006)Depois do jantar eu [svfazia [sNa minha trabalho de casa]] PII16SI2 (F47)

7. *Também eu [sv vou cassar [sN a minha namorado]]. PII16SI44 (F680)

8. *Ela [sv não quer [sNoutra carro]. PII14/15/16SI/II52 (F961)

9. *Pelas nove horas e trinta, fomos a casa e passamos o dia em casa e às vezes [sv visitei [sNas minhas sobrinhos]] em *Amalinda. PIII17SII38 (F803)

10. *[sv Encontrei [snmuitas amigos] e técnicas que vou utilizer no futuro. PIII17SII45 (F918)

11. *[sv fazem [sNmuitas lixos]]. PIII17SII33 (F700)

12. *Há muitos lugares [spcom os belas edifícios]. PIII17SII32 (F675)

13. *Portanto [sN-Suj.uma boa amigo] e uma pessoal real a tudos dos tempos. PIII17SII25 (F561)

14. *[SN- Suj. Boas amigos] suporta, respeitam PIII17SII26 (F594)

15. *bem como [sN eventos climáticas] mais extremos com inudaçoes e secas. PIII15SII1 (F6)

Já no que tange ao que neste artigo se designa outras terminações - terminações $-e$, -em, - $\tilde{a} o,-\phi$, etc. - registraram-se 89 correspondentes a $24 \%$ de desvios, que sedistribuem pelas tendências de usar o masculino e de usar o feminino, como se pode verificar nos exemplos 3. Entretanto, embora comos nomes que terminam com ditongo decrescente (cf. PEIXOTO, 2011, p. 51) como população, pai, mãe, etc. a tendência de associá-los ao feminino supere o uso do masculino, no cômputo geral, também com nomes com terminações diferentes das duas VT tradicionais, o uso desviante do masculino continua a superar o uso do feminino no estabelecimento de CNG.

\section{Exemplos 3}

\section{Outras terminações (uso do masculino)}

1. *Nós [sv víamos [SN o televisão]].

2. *A minha mãe [sv preparará [sNo refeições variadas]].

3. *[F o viagem foi longa e enfadonho]... PII14/15/16SI/II52 (F1017)

4. *os população saudável] PII14/15/16SI/II52 (F1041)

5. *A vida no Harare e [snqualquer outros cidades] no Zimbabwe está muito difícil 
por causa da falta do emprego PIII17SII39 (F820)

6. * [sv Houve [sNmuito performance] ao vivo, e toda gente dançou e as 00.00 vimos alguns fogos de artifício. PIII17SII29 (F637)

7. *[snAlguns qualidades de um bom amigo] são a facilidade e seja confiável, um bom ouvinte, amoroso e cuidadoso. PIII17SII28 (F615)

8. * para criar uma melhor cidade por [SN todos osgerações vindouras]. PIII17SII32 (F689)

\section{Outras terminações (uso do feminino)}

1. *e depois [SV lavav [SN a minha uniforme]] PII16SI47 (F757)

2. * [SV tem [SN muitas animais]]. PII16SI51 (F836)

3. *Ela [SV prepara [SN a jantar]] as sete horas , PII15SII12 (F208)

4. * $\log$ [SV toma [SN uma duche]] PII15SII14 (F240)

5. *[sv Existem [snmuitas hoteis], bem como RainbowTowers e Meikles hotel. PIII17SII37 (F753)

6. *e nunca [sv deixa [sNas amigos] para tras. PIII17SII25 (F551)

7. *Eu comei cous-cas e carne de porco e [sNas legumes], PIII17SII29

8. *Harare é a maior cidade de Zimbabwe com a população de maior [sNuma milhão pessoas]. PIII17SII33 (F692)

O gráfico 1 resume a relação entre a VT e a CNG dos aprendentes de PLE sendo falantes de shona e de inglês. No mesmo pode-se constatar que a maior parte dos nomes com a VT - $a$ é expandida com elementos com traços do masculino.

\section{Gráfico 1: Desvios de $\mathrm{CN}$ em relação à VT}

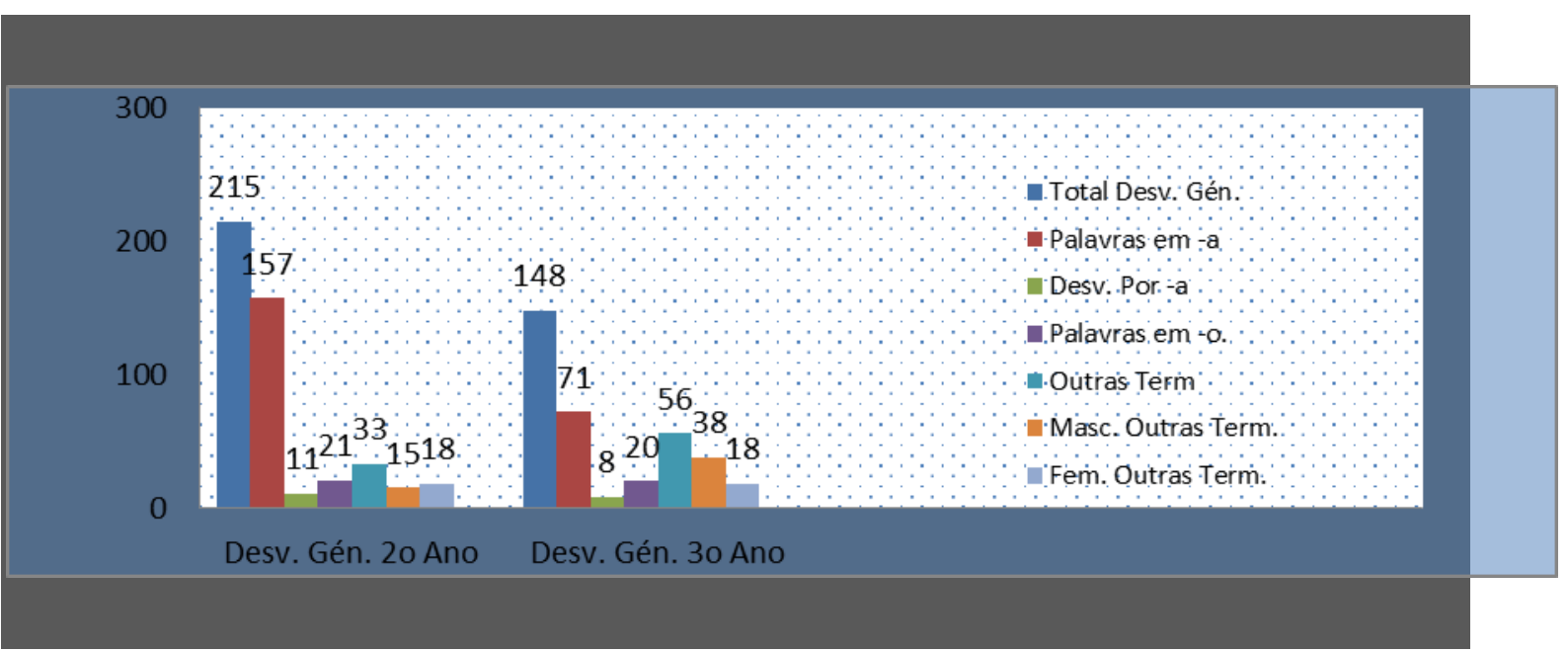




\section{DISCUSSÃO DOS RESULTADOS}

Embora haja muitos casos de nomes que não terminam pelas VT $-a$ e $-o$ e de outros que, apresentando aquelas vogais, não pertencem aos gêneros tradicionalmente a elas associados, aquelas vogais são falsamente consideradas índices do gênero das palavras (VILALVA, $2003^{7}$, p. 922-924 e RIO-TORTO, 2001, p. 263). No entanto, a impossibilidade de $-o$ modificar palavras como mesa para o masculino *meso ou de $-a$ modificar carro para o feminino *carra sustenta a ideia de as VT não constituírem índices de gênero dos nomes.

Desta feita, considerando outros estudos de PLE dos falantes europeus, africanos e asiáticos, nomeadamente, os realizados por Leiria (2006), Pinto (2012) e Ferreira (2011), encontra-se um ponto de divergência das tendências daqueles grupos em relação ao PLE dos falantes de shona e inglês. De acordo com aqueles autores, cujos grupos alvo não eram de falantes de línguas bantu e de inglês, as dificuldades de marcação do gênero gramatical concentram-se em estruturas cujos núcleos nominais não integram as duas classes temáticas $-a \mathrm{e}-o$. Na perspetiva ora considerada, os nomes com a VT $-a e$ $-o$ são, respetivamente, determinados ou modificados por elementos com marcas do feminino e do masculino, coincidindo, muita das vezes com os gêneros feminino e masculino, o que não se verifica nas estruturas de PLE zimbabweano.

Efetivamente, para o caso dos aprendentes zimbabweanos de PLE, nota-se claramente que o gênero atribuído aos acessórios do núcleo nominal não corresponde à VT. Aliás, e para reforçar a ideia de uma tendência generalizada do uso do gênero masculino, a esmagadora maioria de estruturas com núcleos com a VT - $a$ é associada a acessórios com marcas do masculino. Portanto, em função dos dados, não se pode considerar que os alunos desta pesquisa aplicam a marca do gênero aos determinantes e adjetivos em função da VT do núcleo e, consequentemente, não se pode associar o desvio/dificuldade de estabelecer a CNG com a não ocorrência daquelas vogais nas terminações dos núcleos de SN. Trata-se, portanto, de um aspeto que se pode explicar pela assistematicidade do processo de marcação do gênero em português, associada à questão de interlíngua.

Assim, os resultados deste estudo, os quais indicam a concentração dos desvios em SNs com núcleos com a VT $-a$ e a tendências de usar o masculino, invalidam a hipótese 4 
sobre a generalização da dependência dos desvios de CNG em relação às terminações dos nomes; e deixa-se em aberto a discussão apresentada na introdução deste trabalho.

\section{CONSIDERAÇÕES FINAIS}

A relação entre as VT e o fenômeno de CNG não se manifesta de maneira uniforme em todos os aprendentes do PLE, dado que o CLP, sobretudo o que diz respeito aos processos de marcação do gênero e de $\mathrm{CNG}$, o qual se espera que seja particular a cada grupo, desempenha, de maneira diferente, um papel relevante na aprendizagem e uso de PLE. A análise dos dados de aprendentes de PLE sendo falantes de shona e inglês e, portanto, com um perfil sociolinguístico diferente dos grupos estudados por outros autores, revela aspetos diferentes. Para este grupo, as VT não influem no estabelecimento da $\mathrm{CNG}$, diferentemente do que se revelou sobre aqueles. Assim, esta constatação apela, em primeiro lugar, para a consideração de cada contexto em que se ensine português e as idiossincrasias sociolinguísticas dos respetivos aprendentes. Em segundo, considerando o reduzido número de estudos com resultados semelhantes sobre o PLE na região (África Austral), onde a maioria tem perfis linguísticos semelhantes - falantes de uma língua bantu e de inglês - o estudo apela também para a realização de mais estudos de caso que tragam à superfície aspetos referentes à relação entre as VT e CNG em PLE, o que enriquecerá a discussão sobre o assunto e, permitirá verificar até que ponto se pode generalizar esta tendência (uso do masculino com nomes terminados em $-a$ ) no seio de aprendentes e falantes de PLE da região.

\section{REFERÊNCIAS}

BECHARA, E. Moderna Gramática Portuguesa. Rio de Janeiro: Editora Lucerna, 1999.

BOCK, K. e EBHERARD, K. M. Meaning, sound and syntax in english number agreement. In: Language and cognitiveprocess, v. 8, n.1, 1993, p. 57-99. Disponível em:

http://internal.psychology.illinois.edu/ jkbock/bockpubs/Bock\%20Eberhard\%201993.p df. Acesso em: 14 Abril 2017.

CARVALHO, J. G. H. Género. In: Enciclopédia verbo luso-brasileira da cultura, vol. 13. Lisboa/São Paulo: Verbo, 2000, pp. 183-186.

CARVALHO, J. G. H. Teoria da linguagem, vol. 2. Coimbra: Atlântida Editora, 1979. 
CORBERT, G. G. Grammatical gender. In: HOLMES J, \&. MEYERHOFF, M. (eds.), The handbook of language and gender. Oxford: Blackwell, 2006, p. 749-756. Disponível em: http://www.surrey.ac.uk/LIS/SMG/Gender\%20grammatical.pdf. Acesso: 14 Abril 2017.

CUNHA, C. e CINTRA, L. F. Nova gramática do português contemporâneo. Lisboa: Editora Sá da Costa, $1999^{15}$.

DÉCHAINE, R. M. et al. The internal syntax of shona class prefixes. Language Sciences, v. 43, 2014, pp.18-46.

FERREIRA, T. S. Padrões na aquisição/aprendizagem da marcação do gênero nominal em português como L2. Dissertação (Mestrado), Universidade de Coimbra, 2011.

GONÇALVES, P. A gênese do português de Moçambique. Lisboa: Imprensa Nacional Casa da moeda, 2010.

JON-AND, A. Variação, contacto e mudança linguística em Moçambique e Cabo Verde: a concordância variável de número em sintagmas nominais do português. Tese (Doutoramento), Universidade de Estocolmo, 2011.

KLEIN, W. L'Aquisition de la Langue Étrangère. Paris: Ed. Armand Colin, 1989.

LABOV, W. Sociolinguística: uma entrevista com William Labov. Revista Virtual de Estudos da Linguagem - ReVEL. v. 5, n. 9; 2007. Tradução de Gabriel de Ávila Othero. Disponível em: http://www.revel.inf.br/pt Acesso 14 Abril 2017.

LEIRIA, I. Léxico, Aquisição e Ensino do Português Europeu língua não materna. Lisboa: Fundação Calouste Gulbenkian, Fundação para a Ciência e a Tecnologia, 2006, pp. 201-202.

LEIRIA, I. Português Língua Segunda e Língua Estrangeira: Investigação e Ensino. In: Idiomático. Revista Digital de Didáctica de PLNM, nº 3, Centro Virtual Camões, 2004.

LUCCHESI, D.A concordância de gênero. In: LUCCHESI, D., BAXTER, A., e RIBEIRO, I., (orgs.). O português afro-brasileiro. Salvador: EDUFBA, 2009, pp. 295318. ISBN 978-85-232-0875-2. Disponível em: SciELO Books <http://books.scielo.org>. Acesso: 14-04-2017.

MARTINS, C. Número e gênero nominais no desenvolvimento das interlínguas de aprendentes do português europeu como língua estrangeira. Revista Científica da UEM: Série Letras e Ciências Sociais, v.1, n.1, 2015, pp. 26-51. Disponível em: http://www.revistacientifica.uem.mz/index.php/seriec/article/view/93/54. Acesso: 14 Abril 04-2017.

MHUTE, I. The shona subject relation. Tese (Doutorado), University of South Africa, 2011.

MKANGANWI, K. G. Shona (derivational) Morphology: An Observation in Search of a Theory". Zambezi , v. 29, n.2, 2002, pp. 174-190. 
PINTO, J. A aquisição de português LE por alunos marroquinos: Dificuldades interlinguísticas. In:Atas del II congreso internacional SEEPLU - Difundir la lusofonia Cáceres: SEEPLU / CILEM / LEPOLL, 2012. Disponível em: http://www.seeplu.galeon.com/textos2/pinto.pdf . Acesso: 14 Abril 2017.

RIO-TORTO, G. M. Fonética, fonologia e morfologia do português. Lisboa: Colibri, 1998.

RIO-TORTO, G. M. Classes gramaticais: sua importância para o ensino da morfossintaxe, Máthesis, v.10, 2001, pp. 259-286. Disponível em: http://www4.crb.ucp.pt/Biblioteca/Mathesis/Mat10/mathesis10_259.pdf Acesso: 14 Abril 2017.

SALOMÃO, A. C. B. Variação e mudança linguística: panorama e perspectivas da sociolinguística variacionista no brasil. Fórum Lingüístico, v. 8, n. 2, 2011, pp. 187-207, jul./dez. 2011 Disponivel em: http://dx.doi.org/10.5007/1984-8412.2011v8n2p187. Acesso: 02 Março 2017.

SILVEIRA, D. T. e CÓRDOVA, F. P. Pesquisa Científica. In: GERHARDT, T. E. e SILVEIRA, D. T. (org.). Métodos de Pesquisa. Porto Alegre: Editora da UFRGS, 2009.

TRÉZ, T. A. Caracterizando o método misto de pesquisa na educação: Um continuum entre a abordagem qualitativa e quantitativa. In: Atas de pesquisa em educação PPGE/ME, V 7, 2012. pp. 1132-1157. Disponível em: http://proxy.furb.br/ojs/ index.php/ atosdepesquisa/article/view/1132/2235. Acesso em 13 Outubro 2016.

VAN BERKUM, J.J.A.The psycholinguistics of grammatical gender: Studies in language comprehension and production. Tese (Doutoramento), Max Planck Institute for Psycholinguistics. Nijmegen, Netherlands, 1996.

VILALVA, A. Estruturas morfológicas básicas. In: MATEUS, M.H.M et al.Gramática da língua portuguesa. Lisboa: Caminho, $2003^{7}$.

Estruturas morfológicas: unidades e hierarquias nas palavras de português. Lisboa: Dicempto, 1994.

VILELA, M. Gramática da língua portuguesa. Coimbra: Almedina, 1999².

WAGNER, S. Gender in English pronouns. Tese (Doutorado). Albert-LudwigstUniversiatt, 2003. 